Research paper

\title{
1,4-Cyclohexanedicarboxylato-bridged cobalt coordination polymers: Synthesis, crystal structures and magnetic properties
}

\author{
Luis D. Rosales-Vázquez a , Víctor Sánchez-Mendieta a,b,*, Iván García-Orozco a , Susana Hernández-López a , \\ Diego Martínez-Otero $^{\mathrm{b}}$, Raúl A. Morales-Luckie ${ }^{\mathrm{b}}$, Roberto Escudero ${ }^{\mathrm{c}}$, Francisco Morales ${ }^{\mathrm{c}}$ \\ ${ }^{a}$ Facultad de Química, Universidad Autónoma del Estado de México, Paseo Colón y Paseo Tollocan, Toluca, Estado de Mexico 50120, Mexico \\ ${ }^{\mathrm{b}}$ Centro Conjunto de Investigación en Química Sustentable UAEM-UNAM, Carretera Toluca-Ixtlahuaca km. 14.5, Tlachaloya, Toluca, Estado de Mexico, Mexico \\ ${ }^{\mathrm{c}}$ Instituto de Investigaciones en Materiales, Universidad Nacional Autónoma de México, Apartado Postal 70-360, Ciudad de Mexico 04510, Mexico
}

\section{A R T I C L E I N F O}

\section{Article history:}

Received 13 September 2017

Received in revised form 3 November 2017

Accepted 3 December 2017

Available online 6 December 2017

\section{Keywords}

Co polymers

1,4-Cyclohexandicarboxylato

1,10-Phenantroline

Dialkyl-2,2'-bipyridines

Magnetism

\begin{abstract}
A B S T R A C T
Three coordination polymers have been synthesized, using self-assembly solution reactions at ambient conditions, combining $\mathrm{Co}(\mathrm{II})$ ion with 1,4-ciclohexanedicarboxylic acid, in the presence of 1,10-phenantrolione and two different 2,2'-bipyridines, as co-ligands: [ $\mathrm{Co}\left(\mathrm{H}_{2} \mathrm{O}\right)(\mathrm{cdc})($ phen $\left.)\right]_{\mathrm{n}}(\mathbf{1}) ;\left\{\left[\mathrm{Co}\left(\mathrm{H}_{2} \mathrm{O}\right)(\mathrm{cdc})(4 \mathrm{dmb})\right]\right.$. $\left.2 \mathrm{H}_{2} \mathrm{O}\right\}_{\mathrm{n}}(2) ; \quad\left\{\left[\mathrm{Co}\left(\mathrm{H}_{2} \mathrm{O}\right)(\mathrm{cdc})(5 \mathrm{dmb})\right] \cdot 3 \mathrm{H}_{2} \mathrm{O}\right\}_{\mathrm{n}}$ (3), where $\quad \mathrm{cdc}=e, a$-cis-1,4-ciclohexanedicarboxylato, phen $=1,10$-phenantroline, $4 \mathrm{dmb}=4,4^{\prime}$-dimethyl-2,2'-bipyridine, and $5 \mathrm{dmb}=5,5^{\prime}$-dimethyl-2,2'-bipyridine. Crystallographic studies show that these compounds have one-dimensional (1D) structures; $\mathrm{Co}$ (II) in 1-3 is six-coordinated with a distorted-octahedral coordination sphere. Complexes $\mathbf{2}$ and $\mathbf{3}$ exhibit a novel bridging motif of the cdc ligand in its equatorial, axial cis configuration. In addition, the solid-state self-assembly of the polymeric structure of 1 gives rise to a 2D supramolecular framework, mainly through hydrogen bonding. In contrast, complex 2 forms an infinite 1D supramolecular array, made of double Co ion rows bridged by hydrogen bonding interactions. Complex 3 generates an intricate 2D supramolecular framework also throughout hydrogen bonding. The thermal stabilities of the three coordination polymers were investigated. Magnetic properties measurements reveal that complexes 1-3 exhibit weak antiferromagnetic ordering with $\theta_{(C-W)}=-9.6,-5.8$ and $-7.5 \mathrm{~K}$, and $E_{2}=0.51,0.16$ and $0.28 \mathrm{~cm}^{-1}$, accordingly to Curie-Weiss model and Rueff phenomenological approach, respectively.
\end{abstract}

(c) 2017 Elsevier B.V. All rights reserved.

\section{Introduction}

The design of hybrid metal-organic polymeric and supramolecular architectures, based on crystal engineering, has gained substantial interest in recent years in coordination chemistry, supramolecular chemistry and materials science, since these structures can acquire fascinating arrays and work as functional materials [1]. Crystal engineering refers to the construction of crystal structures from organic and metal-organic compounds using design principles that come from an understanding of the intermolecular interactions in the molecular solids [2]. Several strategies have been developed to synthesize metal mixed ligands coordination polymers of bivalent transition metals containing nitrogen and oxygen donor ligands [3]. Self-assembly of small molecules, compounds or complexes, proved to be a valuable pro-

* Corresponding author at: Facultad de Química, Universidad Autónoma del Estado de México, Paseo Colón y Paseo Tollocan, Toluca, Estado de Mexico 50120, Mexico.

E-mail address: vsanchezm@uaemex.mx (V. Sánchez-Mendieta). cedure for the synthesis of large structures with a minimum of effort. However, the self-assembly process is sometimes accompanied by an uncertainty halo, due to unpredictable interactions among metal centers and ligands, especially when weak forces (e.g. hydrogen bonding, $\pi-\pi$ interactions) and/or solvents, such as water, are involved [4]. Also, supramolecular frameworks based on metal centers and organic ligands have gained interest recently, due to their fascinating structural diversity and their potential applications in catalysis, sensing, porosity and non-linear optics [5]. Among the most used bridging ligands for transition metals are the dicarboxylates [6]. Perhaps the main reason to keep investigating the dicarboxylates as bridging ligands of metal centers, is the, at times, surprising variety of coordination modes that these organic compounds can accomplish, yielding thus interesting extended metal-organic molecular and supramolecular structures possessing divergent dimensionalities and properties [7]. Coordination polymers having cdc as bridging ligand have been prepared, though no so extensive; moreover, most of those compounds have been synthesized using solvothermal or hydrothermal methods [8]. The use of 2,2'-bipyridine as an ancillary ligand had become 
relevant in our previous studies on complexes [9] and coordination polymers [10] of different metals. Therefore, we decided to continue with one of the most studied nitrogen donor ligands [11], but varying its alkyl substituent, in order to verify the influence of the co-ligand on the dimensionalities and crystalline structures of the resulting coordination polymers. So far, few articles have been published on the use of different di-alkyl-2,2'-bipyridines as ancillary ligands, either in transition metal complexes [12] or coordination polymers $[13,14]$.

In this article, we describe the synthesis, crystalline molecular and supramolecular structures, thermal analyses and magnetic properties of three coordination polymers of three coordination polymers of formulae $\left[\mathrm{Co}\left(\mathrm{H}_{2} \mathrm{O}\right)(\mathrm{cdc})(\text { phen })\right]_{\mathrm{n}}(\mathbf{1}),\left\{\left[\mathrm{Co}\left(\mathrm{H}_{2} \mathrm{O}\right)(\mathrm{cdc})\right.\right.$ $\left.(4 \mathrm{dmb})] \cdot 2 \mathrm{H}_{2} \mathrm{O}\right\}_{\mathrm{n}}(2)$ and $\left\{\left[\mathrm{Co}\left(\mathrm{H}_{2} \mathrm{O}\right)(\mathrm{cdc})(5 \mathrm{dmb})\right] \cdot 3 \mathrm{H}_{2} \mathrm{O}\right\}_{\mathrm{n}}(\mathbf{3})(\mathrm{cdc}=$ e,a-cis-1,4-ciclohexanedicarboxylato, phen $=1,10$-phenantroline, $4 \mathrm{dmb}=4,4^{\prime}$-dimethyl-2,2'-bipyridine, and $5 \mathrm{dmb}=5,5^{\prime}$-dimethyl2,2'-bipyridine).

\section{Experimental section}

\subsection{General considerations}

All chemicals were of analytical grade, purchased commercially (Aldrich) and used without further purification. All syntheses were carried out under aerobic and ambient conditions. Elemental analyses for $\mathrm{C}, \mathrm{H}, \mathrm{N}$ were obtained by standard methods using a Vario Micro-Cube analyzer. IR spectra of the complexes were determined in a FT-IR Shimadzu spectrophotometer, IR Prestige-21, from 4000 to $500 \mathrm{~cm}^{-1}$. Thermogravimetric analyses were performed in a SDT Q600 TA Instruments analyzer, under $\mathrm{N}_{2}$ atmosphere, at a heating rate of $10^{\circ} \mathrm{C} \mathrm{m^{-1 }}$, from 20 to $700{ }^{\circ} \mathrm{C}$. Magnetic characteristics of the complexes were determined with a MPMS Quantum Design magnetometer, with measurements performed at zero field cooling (ZFC) and field cooling (FC) from 2 to $300 \mathrm{~K}$ and decreasing. The applied magnetic field was $1000 \mathrm{Oe}$, and diamagnetic corrections were estimated using Pascal's constants as $-250 \times 10^{-6} \mathrm{~cm}^{3} \mathrm{~mol}^{-1}$.

\subsection{Preparation of $\left[\mathrm{Co}\left(\mathrm{H}_{2} \mathrm{O}\right)(\mathrm{cdc})(\text { phen })\right]_{n}(\mathbf{1})$}

Initially, sodium 1,4-cyclohexanedicarboxylate was prepared by adding an aqueous solution of $\mathrm{NaOH}(5 \mathrm{~mL} ; 0.16 \mathrm{M})$ to a methanol solution ( $5 \mathrm{~mL}$ ) of 1,4-cyclohexanedicarboxylic acid (0.0688 g; 0.4 $\mathrm{mmol})$. A solution of 1,10 -phenantroline $(0.0744 \mathrm{~g} ; 0.4 \mathrm{mmol})$ in methanol $(5 \mathrm{~mL})$ was added to the solution of sodium 1,4-cyclohexanedicarboxylate while stirring. Then, a de-ionized water solution $(10 \mathrm{~mL})$ of $\mathrm{Co}\left(\mathrm{NO}_{3}\right)_{2} \cdot 6 \mathrm{H}_{2} \mathrm{O}(0.1164 \mathrm{~g} ; 0.4 \mathrm{mmol})$ was added. A red-brown translucent solution was obtained. After five days, purple-brown crystals were achieved; these were filtered out and washed with de-ionized water. Yield: $49 \%$ based on metal precursor. Elemental analysis (\%), $\mathrm{C}_{20} \mathrm{H}_{20} \mathrm{~N}_{2} \mathrm{O}_{5} \mathrm{Co}$, cal.: C, 56.21; $\mathrm{H}, 4.71 ; \mathrm{N}$, 6.55; found: C, 56.25; H, 4.64; N, 6.50. IR cm ${ }^{-1}$ (ATR): 3228 (m, br), 2924 (m), 1554 (s), 1516 (m), 1427 (m), $1404(\mathrm{~m}), 1203$ (s), 1146 (s), 964 (s), 910 (s), 841 (m, sh), 725 (m, sh), 671 (m, sh).

\subsection{Preparation of $\left\{\left[\mathrm{Co}\left(\mathrm{H}_{2} \mathrm{O}\right)(\mathrm{cdc})(4 \mathrm{dmb})\right] \cdot 2 \mathrm{H}_{2} \mathrm{O}\right\}_{n}$ (2)}

Comparable conditions as in the synthesis of $\mathbf{1}$ were used, except that a solution of 4,4-dimetil-2,2'-bipyridine ( $0.0720 \mathrm{~g}$; $0.4 \mathrm{mmol})$ in methanol $(10 \mathrm{~mL})$ was added to the solution of sodium 1,4-cyclohexanedicarboxylate while stirring. Yield: $43 \%$ based on metal precursor. Elemental analysis (\%), $\mathrm{C}_{20} \mathrm{H}_{28} \mathrm{~N}_{2} \mathrm{O}_{7} \mathrm{Co}$, cal.: C, 51.39; H, 6.03; N, 5.99; found: C, 51.06; H, 6.02; N, 6.03. IR cm ${ }^{-1}$ (ATR): 3259 (m, br), 2943 (w), 1616 (m, sh), 1538 (s), 1512 (m), 1457 (m, sh), 1409 (s), 1014 (w, sh), 914 (m), 829 (m, sh), 767 (m, sh).

\subsection{Preparation of $\left\{\left[\mathrm{Co}\left(\mathrm{H}_{2} \mathrm{O}\right)(\mathrm{cdc})(5 \mathrm{dmb})\right] \cdot 3 \mathrm{H}_{2} \mathrm{O}\right\}_{n}$ (3)}

Similar conditions as in the synthesis of $\mathbf{1}$ were used, except that a solution of 5,5'-dimethyl-2,2'-bpyridina ( $0.0720 \mathrm{~g} ; 0.4$ $\mathrm{mmol})$ in methanol $(10 \mathrm{~mL})$ was added to the solution of sodium 1,4-cyclohexanedicarboxylate. Yield: $64 \%$ based on metal precursor. Elemental analysis (\%), $\mathrm{C}_{20} \mathrm{H}_{30} \mathrm{~N}_{2} \mathrm{O}_{8} \mathrm{Co}$, cal.: C, 49.49; $\mathrm{H}, 6.23$, N, 5.77; found: C, 50.02; H, 6.05; N, 5.58. IR cm c $^{-1}$ (ATR): 3420 (w, br), 2940 (w, sh), 1527 (s), 1470 (m, sh), 1427 (m, sh), 1404 (s, sh), 1349 (m, sh), 1254 (m, sh), 1144 (w, sh), 1044 (m, sh), 902 (w, sh), 841 (m, sh), 757 (m, sh), 687 (m, sh), 587 (m, sh).

\section{X-ray crystallography}

Crystallographic data for $\mathbf{1 - 3}$ were collected on a Bruker APEX II CCD Diffractometer, for $\mathbf{1}$ and $\mathbf{2}$ at $100 \mathrm{~K}$ and for $\mathbf{3}$ at $296 \mathrm{~K}$, using Mo-K $\alpha$ radiation $(k=0.71,073 \AA$ ) from an Incoatec $\mathrm{I} \mu \mathrm{S}$ source and Helios optic monochromator [15]. Suitable crystals were coated with hydrocarbon oil (Parabar), picked up with a nylon loop, and mounted in the cold nitrogen stream of the diffractometer. The structures were solved using intrinsic phasing (SHELXT) [16] and refined by full-matrix least-squares on $\mathrm{F}^{2}$ [16] using the shelXle GUI [17]. The hydrogen atoms of the $\mathrm{C}-\mathrm{H}$ bonds were placed in idealized positions whereas the hydrogen atoms from water molecules were localized from the difference electron density map, and their position was refined with $\mathrm{U}_{\mathrm{iso}}$ tied to the parent atom with distance restraints. In compound $\mathbf{2}$, the hydrogens from water molecules that are not coordinated to cobalt present positional disorder in two positions, the occupation was set at $50 \%$ and their position were localized from the difference electron density map and refined using DFIX instruction. The hydrogens for methyl group (C11) present positional disorder in two positions that was solved using AFIX 123 constraint to fix the positions of hydrogens and the occupancy was fixed in 50\%. The crystallographic data and refinement details for the polymers are summarized in Table S1. Selected bond lengths, angles and hydrogen bonding interactions for 1-3 are listed in Tables S2, S3 and S4, respectively.

\section{Results and discussion}

\subsection{Synthesis and IR spectra}

Using a very simple methodology of self-assembling solution reactions, equivalent amounts of 1,4-cyclohexanedicarboxylic acid, $\mathrm{Co}\left(\mathrm{NO}_{3}\right)_{2}$, and 1,10-phenantroline, 4,4'-dimethyl-2,2'-bipyridine and 5,5'-dimethyl-2,2'-bipyridine, respectively, were mixed in water-methanol solutions under ambient conditions. Slow evaporation of solvents yielded reddish-brown crystals of complexes 1-3. These crystals are insoluble in common solvents.The IR spectra of the complexes show the typical bands (vide supra) expected for carboxylate ligands coordinated to $\operatorname{Co}(\mathrm{II})[18,19]$, along to the bands corresponding to the auxiliary ligands (Figs. S1-S3). Since the cdc bridging ligand has the same coordination modes in polymers 1-3, relatively few variances can be observed in the IR spectra of these complexes. These IR spectra show two sets of asymmetric stretches for the carboxylate moiety at 1554 and $1516 \mathrm{~cm}^{-1}, 1538$ and $1512 \mathrm{~cm}^{-1}, 1527$ and $1470 \mathrm{~cm}^{-1}$, with the corresponding symmetric stretches at 1404 and $1427 \mathrm{~cm}^{-1}, 1409$ and 1457, 1404 and 1427 for 1-3, respectively. The differences between asymmetric and symmetric stretch for the carboxylate ion $\left(\Delta v_{\mathrm{COO}}^{-}, \mathrm{cm}^{-1}\right)$ are 150 and 89,129 and 55 , and 123 and 43 , for 1-3, respectively. These sets of bands can be assigned, correspondingly, to the bidentate chelate and monodentate coordination modes of the cdc ligand found in these complexes [20]. 


\subsection{Structural description of $\left[\mathrm{Co}\left(\mathrm{H}_{2} \mathrm{O}\right)(\mathrm{cdc})(\text { phen })\right]_{n}(\mathbf{1})$}

1 crystallizes in a monoclinic system with $P 2_{1} / c$ space group and forms an infinite one dimensional (1D) coordination polymer (Fig. 1). In fact, a complex almost identical to polymer $\mathbf{1}$ has been reported previously and its structural characterization has been analyzed [21]. However, that isostructural compound, with a different empirical formula, was obtained under hydrothermal conditions (about $180^{\circ} \mathrm{C}$ for 6 days), whereas we synthesize the same compound at ambient conditions, using a very simple methodology; and, besides thermogravimetric analysis, no further properties were reported [21]. The repeat molecular unit of $\mathbf{1}$ contains one Co center, one cdc ligand, one phen co-ligand and one coordinated water ligand. The coordination environment of the Co is shown in Fig. S4a; the metal is six-coordinated and surrounded by four oxygen atoms from two different cdc ligands and the aqua ligand, and two nitrogen atoms from one phen ligand. The Co has a

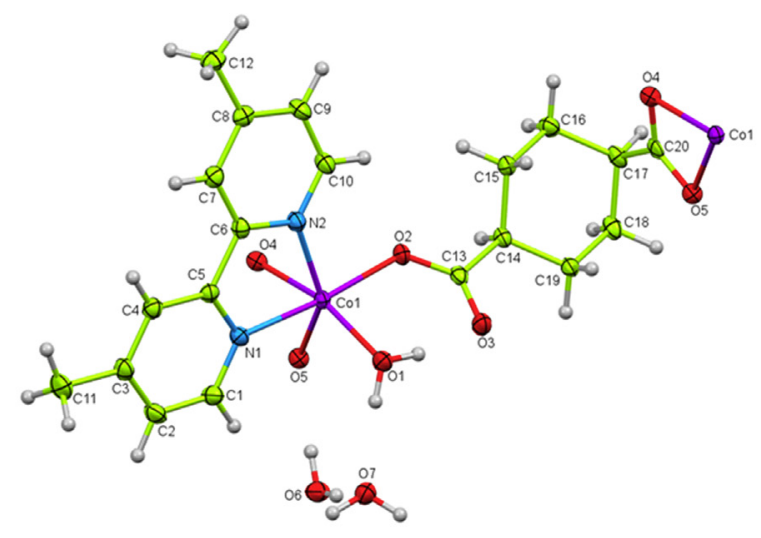

a

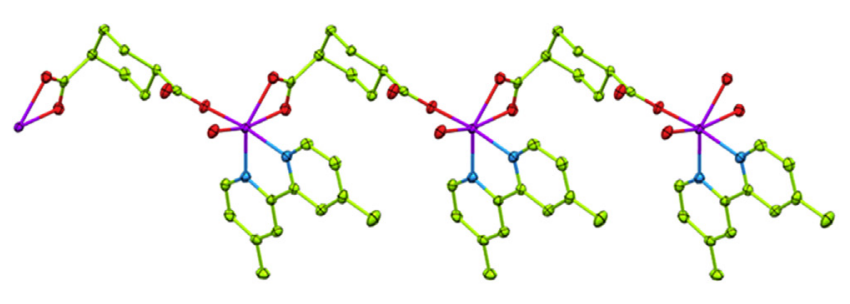

b

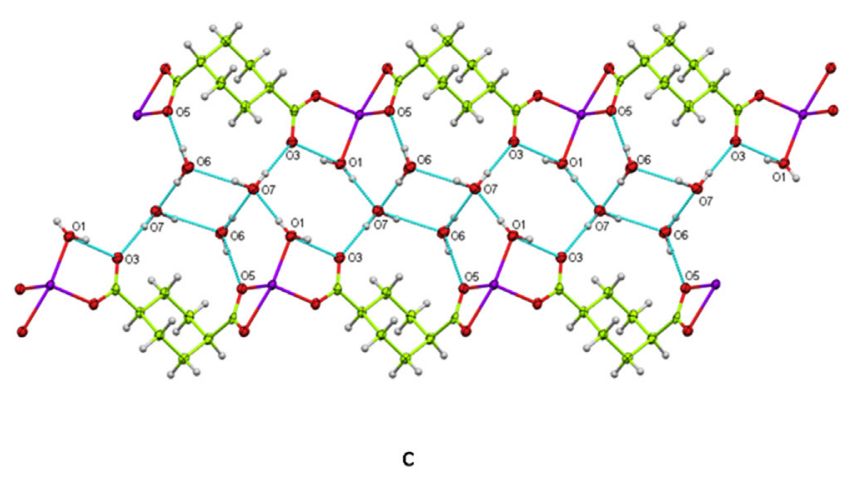

Fig. 1. Molecular structure of $\left\{\left[\mathrm{Co}\left(\mathrm{H}_{2} \mathrm{O}\right)(\mathrm{cdc})(4 \mathrm{dmb})\right] \cdot 2 \mathrm{H}_{2} \mathrm{O}\right\}_{\mathrm{n}}(2)$ (ellipsoids shown at $60 \%$ probability) (a); $1 \mathrm{D} \mathrm{V}$-shape polymer chain of 2 ; hydrogens are omitted for clarity (b); 1D supramolecular array in $2 ; 4 \mathrm{dmb}$ ligand is omitted for clarity (c). distorted octahedral configuration. The Co-O bond lengths range from 2.0502(12) to 2.1774(12) $\AA$, while the Co-N distances are $2.1100(14)$ and $2.1370(14) \AA$, these values are comparable to those found on similar $\mathrm{Co}(\mathrm{II})$ compounds [22-24]. In complex 1, a 1D zigzag chain is formed due to the combined monodentate $\eta^{1}$ and chelate bidentate $\eta^{2}$ coordination modes of cdc, together with the equatorial, axial cis configuration of its carboxylate groups, thus bridging the Co ions (Fig. S4b). Intermolecular hydrogen-bonding interactions assemble complex 1 into a 2D supramolecular array. These interactions are promoted mainly by the presence of the aqua ligand and the non-coordinated oxygen atom of the cdc carboxylate. This is shown in Fig. S4c, where the main $\mathrm{O}-\mathrm{H}$. . .O interactions involve the $\mathrm{O}-\mathrm{H}$ moiety (O5) of the aqua ligand with each oxygen atom $(\mathrm{O} 2)$ of the non-coordinated side of one cdc ligand, in an intramolecular hydrogen bond. Furthermore, each water ligand (05) generates a double hydrogen bridge; the one described above, and another with one cdc oxygen atom (O3) coordinated to $\mathrm{Co}(\mathrm{II})$ of a neighboring 1D polymeric chain (intermolecular hydrogen bonding). In this way, an extended 2D supramolecular array is generated (Fig. S4c), in which, the intermolecular shortest Co. . .Co distance is $5.431 \AA$.

\subsection{Structural description of $\left\{\left[\mathrm{Co}\left(\mathrm{H}_{2} \mathrm{O}\right)(\mathrm{cdc})(4 d m b)\right] \cdot 2 \mathrm{H}_{2} \mathrm{O}\right\}_{n}$ (2)}

2 crystallizes in a monoclinic system with $P 2_{\mathbf{1}} / c$ space group and forms an infinite 1D coordination polymer. The asymmetric unit contains one $\mathrm{Co}(\mathrm{II})$ ion, one cdc ligand, one $4 \mathrm{dmb}$ co-ligand, one aqua ligand and other two free water molecules. The coordination environment of the Co is shown in Fig. 1a; the metal center is six-coordinated and surrounded by four oxygen atoms from two different cdc ligands and the aqua ligand, and two nitrogen atoms from one $4 \mathrm{dmb}$ ligand. As in 1, the Co ion has a distorted octahedral configuration. The Co-O bond lengths range from 2.0547(10) to $2.18,711(10) \AA$, while the Co-N distances are $2.0867(12)$ and 2.1377(12) $\AA$, these values are like those found on related $\mathrm{Co}(\mathrm{II})$ compounds [25]. In complex 2, a 1D chain is formed due to the combined monodentate $\eta^{1}$ and chelate bidentate $\eta^{2}$ coordination modes of cdc, along with the equatorial, axial cis configuration of its carboxylate groups bridging the metal centers (Fig. 1b). The way all Co ions align to one side of the 1D chain, with the cdc ligand completing a V-shaped "repeat unit" (Fig. 2b), is a new motif found in coordination polymers bearing the cdc bridging ligand. T.F. Liu, et al., have reported most of the motifs originated for this cdc ligand, in both, trans and cis conformations, while forming coordination polymers [26]. Thus, this type of novel motif has not been noticed neither in the equatorial, axial cis nor in the equatorial, equatorial trans conformations of cdc bridging ligand. There is only one report of a similar motif in a $\mathrm{Cu}$ (II) coordination polymer built on cdc and phenantroline [27]; nonetheless, authors did not comment on the cdc motif obtained.

Hydrogen-bonding interactions assemble complex 2 into a 1D supramolecular array with two-row of Co centers (Fig. 1c). These bindings are carried out by the presence of two molecules of water in the crystal, and their interactions with the aqua ligand and coordinated and non-coordinated oxygen atoms of the cdc ligand. This is shown in Fig. 2c, where the main $\mathrm{O}-\mathrm{H}$. . .O interactions involve the $\mathrm{O}-\mathrm{H}$ moiety $(\mathrm{O} 1)$ of the aqua ligand with each oxygen atom (O3) of the non-coordinated side of one cdc ligand, in an intramolecular hydrogen bond. Then, each water ligand (O1) generates a double hydrogen bridge; the one described above, and another with one water of crystallization (07), which, in turn, bridges also with the other water of crystallization (06) and with the non-coordinated side of the cdc ligand (03) (intermolecular hydrogen bonding). In addition, the coordinated side of the cdc ligand (05) makes also a hydrogen bridge with one water of crystallization (06). These hydrogen-bonding fused rings cause the 


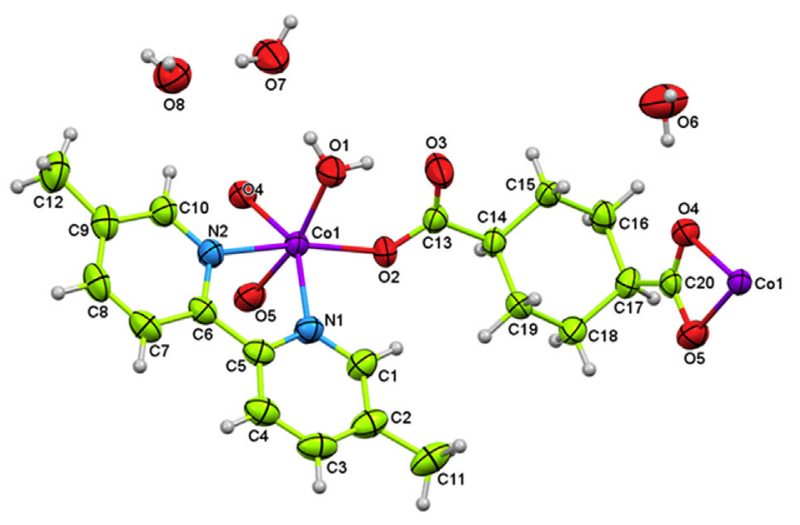

a

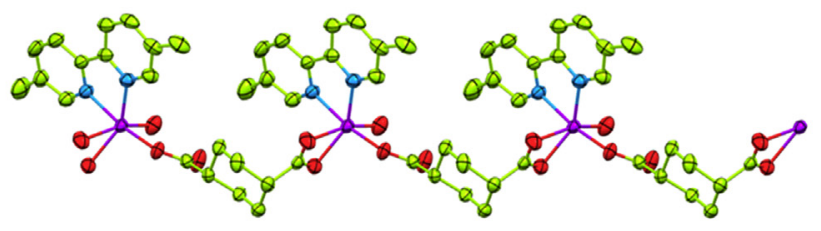

b

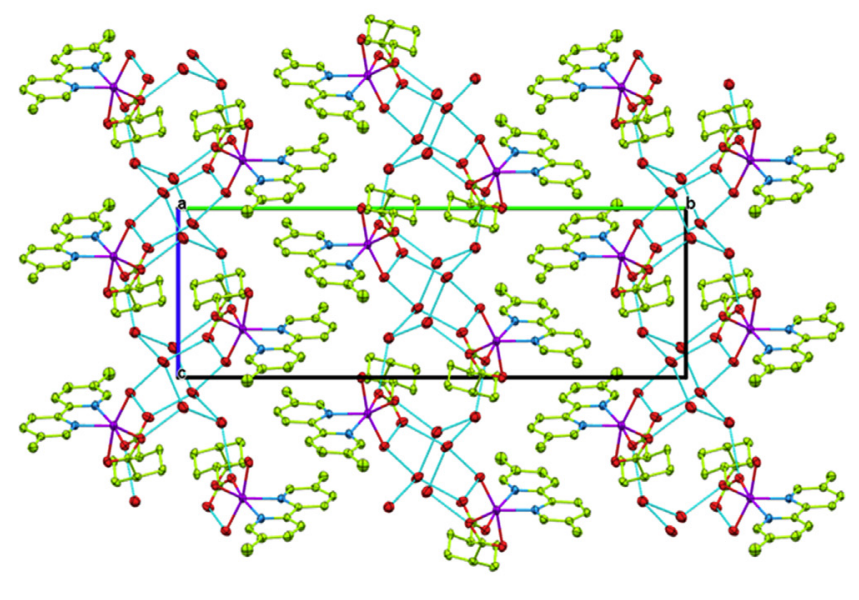

C

Fig. 2. Molecular structure of $\left\{\left[\mathrm{Co}\left(\mathrm{H}_{2} \mathrm{O}\right)(\mathrm{cdc})(5 \mathrm{dmb})\right] \cdot 3 \mathrm{H}_{2} \mathrm{O}\right\}_{\mathrm{n}}(\mathbf{3})$ (ellipsoids shown at $60 \%$ probability) (a); 1D V-shape polymer chain of 3 ; hydrogens are omitted for clarity (b); 2D supramolecular array in 3; $5 \mathrm{dmb}$ ligand is omitted for clarity (c).

merger of two 1D polymeric chains, giving rise to a two-row Co 1D supramolecular system (Fig. 1c, Fig. S5).

\subsection{Structural description of $\left\{\left[\mathrm{Co}\left(\mathrm{H}_{2} \mathrm{O}\right)(\mathrm{cdc})(5 \mathrm{dmb})\right] \cdot 3 \mathrm{H}_{2} \mathrm{O}\right\}_{n}(\mathbf{3})$}

3 crystallizes also in a monoclinic system with $P 2_{1} / c$ space group and forms an infinite 1D coordination polymer. The asymmetric unit contains one $\mathrm{Co}(\mathrm{II})$ ion, one cdc ligand, one $5 \mathrm{dmb}$ coligand, one aqua ligand and other three free water molecules. The coordination environment of the Co is shown in Fig. 2a; the metal center is six-coordinated and surrounded by four oxygen atoms from two different cdc ligands and the aqua ligand, and two nitrogen atoms from one $5 \mathrm{dmb}$ ligand. As in $\mathbf{2}$, the Co ion has a distorted octahedral configuration. The Co-O bond lengths range from $2.0634(13)$ to $2.2118(13) \AA$, while the Co-N distances are 2.0959(14) and 2.1622(13) $\AA$; these values are similar to those found on comparable $\mathrm{Co}(\mathrm{II})$ compounds [21-25]. In complex $\mathbf{3}$, alike 2 , a $1 \mathrm{D}$ chain is formed owing to the combined monodentate $\eta^{1}$ and chelate bidentate $\eta^{2}$ coordination modes of cdc, beside with the equatorial, axial cis configuration of its carboxylate groups bridging the metal centers (Fig. 2b). Analogous to complex 2, in the extended structure of $\mathbf{3}$ the Co metal centers align to one side of the 1D chain, with the cdc ligand forming a kind of V-shaped "repeat unit" (Fig. 2b), which, as mentioned before, is a new motif found in coordination polymers having cdc as bridging ligand [26]

Hydrogen bond interactions gather complex 3 into a 2D supramolecular array (Fig. 2c). These bindings are formed by the presence of three molecules of water in the crystal, and their interactions with the aqua ligand and the coordinated and non-coordinated oxygen atoms of the cdc ligand. Similarly to complex $\mathbf{2}$, the main $\mathrm{O}-\mathrm{H}$...O interactions involve the $\mathrm{O}-\mathrm{H}$ moiety $(\mathrm{O} 1)$ of the aqua ligand with each oxygen atom (03) of the non-coordinated side of one cdc ligand, in an intramolecular hydrogen bond. Also, each aqua ligand (O5) generates a double hydrogen bridge; the one defined above, and another with one water of crystallization (07), which, consecutively, bridges also with the two other water of crystallization molecules (06 and 08 ) and non-coordinated side of the cdc ligand (03) (intermolecular hydrogen bonding). Furthermore, the coordinated side of the cdc ligand (04) creates also a hydrogen bridge with one water of crystallization (06), and this latter makes a bridge also with another water of crystallization (08). These elaborate hydrogen bonding array in $\mathbf{3}$ provokes the formation of six-member fused rings (without including the hydrogen atoms), causing the merger of 1D polymeric chains and generating a chain links type system (Fig. 2c), which grows in the $a$ crystallographic axis giving rise thus to a 2D supramolecular system (Fig. S6).

\subsection{Thermal properties of 1-3}

To examine the thermal stabilities of the crystalline polymers, thermal analyses were performed for the complexes between 20 and $700{ }^{\circ} \mathrm{C}$ (Figure S7). The TGA plots for the three complexes can be analyzed as having three main stages of decomposition. The first weight loss (5.0\%) for $\mathbf{1}$ occurs between 170 and $212{ }^{\circ} \mathrm{C}$; the second, with a weight loss of $7.0 \%$ of the initial weight, takes place approximately between 246 and $339^{\circ} \mathrm{C}$. The final weight loss (44\%) occurs around $342-516{ }^{\circ} \mathrm{C}$. For complex 2, the first weight loss ( 9\%) appears between 76 and $157^{\circ} \mathrm{C}$. The second loss (17\%) starts around $179{ }^{\circ} \mathrm{C}$ and ends at $273^{\circ} \mathrm{C}$. The final loss ( 58\%) occurs from 290 to 495 C, leaving around $14 \%$ of the initial sample weight at $700{ }^{\circ} \mathrm{C}$. In complex 3 , the first weight loss (10\%) occurs between 70 and $127^{\circ} \mathrm{C}$; the second, with a weight loss of $36.0 \%$ of the initial weight, takes place approximately between 286 and $377^{\circ} \mathrm{C}$; and the final weight loss $(\sim 33 \%)$ occurs around $384-483^{\circ} \mathrm{C}$, leaving around $15 \%$ of the initial sample weight at $700{ }^{\circ} \mathrm{C}$. In these three complexes, the first decomposition stages can be ascribed to the loss of water; however, for complex 1 one coordinated water ligands is lost, whilst for complexes $\mathbf{2}$ and $\mathbf{3}$, two and three molecules of water of crystallization are lost, respectively. Additionally, these latter complexes also lost one aqua ligand each. The higher-temperature stages can be attributed to the combined weight loss of the cdc ligand (calcd. $39 \%$ for 1, $36 \%$ for 2 and 35\% for 3), and the phen (calcd. 42\%), $4 \mathrm{dmb}$ (calcd. $39 \%$ ) and $5 \mathrm{dmb}$ (calcd. 38\%) co-ligands, respectively. The residual material, at $700{ }^{\circ} \mathrm{C}$, for complexes 2 and 3, approximates to residual $\mathrm{CoO}$ (calcd. $16 \%$ for $\mathbf{2}$ and $15 \%$ for $\mathbf{3}$ ). It is evident that due to their different structural characteristics, mainly supramolecular, polymer $\mathbf{1}$ has superior thermal stability compared to those of 2 and $\mathbf{3}$ (Fig. S7); so, the residual weight for $\mathbf{1}$ at $700{ }^{\circ} \mathrm{C}$ is approximately $40 \%$. 


\subsection{Magnetic properties of 1-3}

The calculated magnetic susceptibility $\left(\chi_{M}\right)$, in terms of $\mathrm{cm}^{3} \mathrm{~mol}^{-1}$, vs. temperature for $\mathbf{1 - 3}$, can be seen in Figs. 3-5. Although no maximum is observed in the susceptibility plots, the observed increase of $\chi_{M}$, and the decrease in $\chi T$ (Figs. S8-S10), with decreasing temperature, suggests antiferromagnetic coupling, albeit very weak. After fitting the obtained data to Curie-Weiss model:

$\chi_{M}=C /(T-\theta)$

The Curie constants were determined to be, $C=2.76,2.85$ and $2.51 \mathrm{~cm}^{3} \mathrm{~K} / \mathrm{mol}$ for $1-3$, respectively; $S=3 / 2$, with a small orbital contribution, not totally quenched, and influences to a value of orbital angular contribution less than one. The Curie-Weiss temperatures were determined to be $\theta_{(C-W)}=-9.64,-5.83$ and -7.53 $\mathrm{K}$ for 1-3, respectively, indicative of an antiferromagnetic ordering. Regularly, the effects of spin-orbit coupling occur in combination with the effects of a symmetry-lowering structural distortion, for instance away from $\mathrm{O}_{\mathrm{h}}$ symmetry [28], as it is the case for complexes 1-3. From the $\chi T$ values obtained at $300 \mathrm{~K}$, a $\mu_{\mathrm{eff}}=4.7,4.8$ and $4.5 \mu_{\mathrm{B}}$ are calculated for 1-3, respectively, which are higher than the expected spin-only value of $3.87 \mu_{\mathrm{B}}$ corresponding to three unpaired electrons for high-spin $\mathrm{d}^{7}-\mathrm{Co}^{2+}$; however, the obtained value agrees with those reported in literature for highspin Co(II) complexes [29] and confirms an $S=3 / 2$ spin state. These results are in concordance with previous magnetic studies carried out on a $\mathrm{Co}$ (II) complex containing 3,6-ditert-butyl-o-benzosemiquinonato ligands and 5,7-di-tert-butyl-2-(pyridine-2-yl) benzoxazole having distorted octahedral geometry [30]. However, as observed in Figs. 3-5, it was difficult to fit the Curie-Weiss model to the $\chi_{M}$ vs. $T$ plot, particularly below $25 \mathrm{~K}$. Therefore, assuming that in the low-temperature region the spin-orbit coupling is promoted in these systems, the magnetic exchange interactions and the spin-orbit coupling for complexes 1-3 were also estimated based on the simple phenomenological equation:

$\chi_{M} T=A \exp \left(-E_{1} / k T\right)+B \exp \left(-E_{2} / k T\right)$

where $A+B$ is equal to the Curie constant and $E_{1}$ and $E_{2}$ are the "activation energies" of the spin-orbit coupling and the magnetic interaction, respectively [31]. As shown in Figs. 3-5, for the $\chi_{M}$ vs. $T$ plot, Rueff model [32] follows very well the experimental data, even at the lowest temperature studied (Figs. 3-5; Figs. S8-S10). The best parameters obtained with this procedure after least-squares fitting are: $A+B=2.90,3.01$ and $2.59 \mathrm{~cm}^{3} \cdot \mathrm{K} \cdot \mathrm{mol}^{-1}$ for $\mathbf{1 - 3}$, respectively, which agree with values given in the literature for the Curie constant

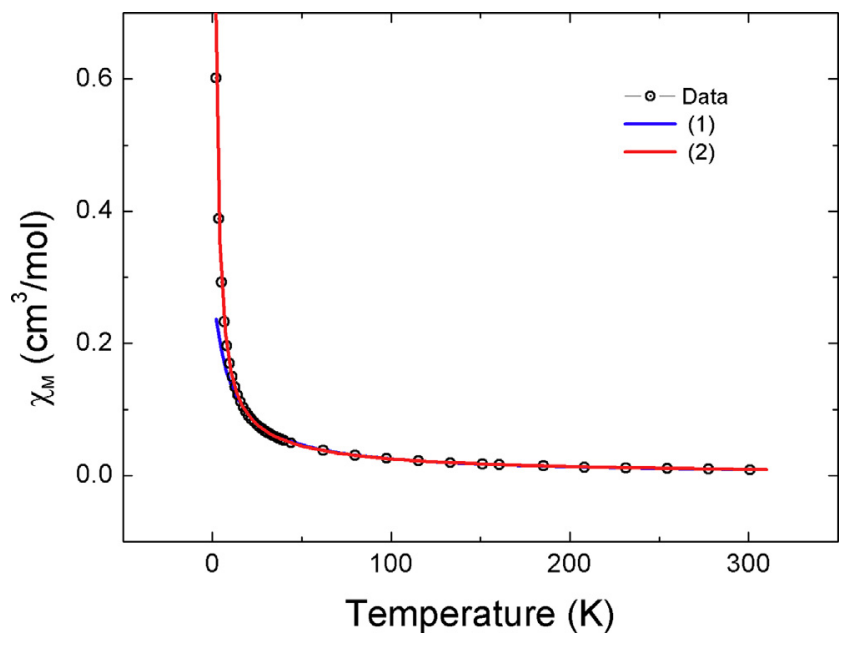

Fig. 3. $\chi_{M}$ vs. $T$ plot for 1

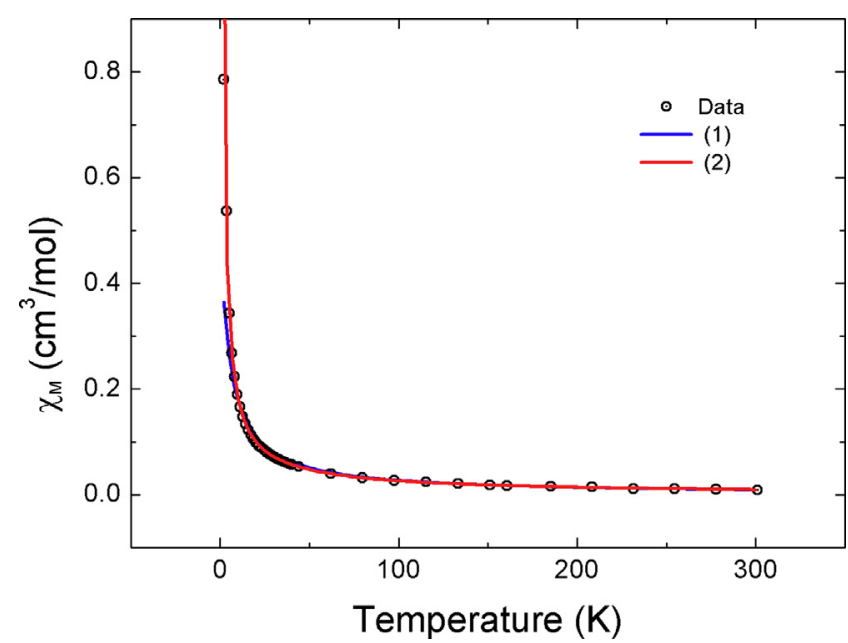

Fig. 4. $\chi_{M}$ vs. $T$ plot for 2 .

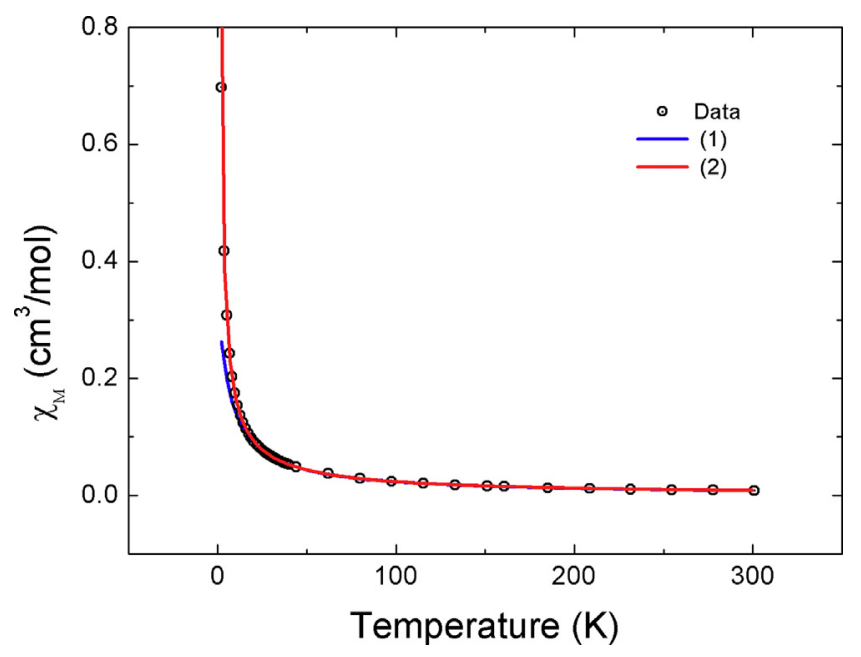

Fig. 5. $\chi_{M}$ vs. $T$ plot for 3 .

$\left(C=2.8-3.5 \mathrm{emu} \cdot \mathrm{K} \cdot \mathrm{mol}^{-1}\right)$, and also practically equals the values obtained from the fitting of Curie-Weiss model showed previously. The effect of the spin-orbit coupling $E_{1}=38.45,37.96$ and 28.32 $\mathrm{cm}^{-1}$ for 1-3, respectively, are lower than values reported for other $\mathrm{Co}$ (II) systems (52 to $65 \mathrm{~cm}^{-1}$ ) [31,32], which, by the way, are not supramolecular systems but rather are extended coordinated compounds. The positive, and low, values of activation energy $E_{2}=$ $0.51,0.16$ and $0.28 \mathrm{~cm}^{-1}$ for $\mathbf{1 - 3}$, respectively, confirms that antiferromagnetic exchanges are effective in these polymers and also that these interactions are weak. These $E_{1}$ and $E_{2}$ values obtained for 1-3 are very similar to those found in a $\mathrm{Co}(\mathrm{II})$-fumarato complex, having a rare distorted-trigonal prismatic geometry, which also has hydrogen bonding interactions yielding a 2D supramolecular structure [33]. Hence, regarding the fitting of Eq. (2) to these divergent systems, it seems that the difference in coordination geometry does not influence significantly the $\mathrm{Co}$ (II) spin-orbit coupling and the magnetic interaction (E1 and E2 values), but rather are the distances among metal ions in the supramolecular arrays the important factor; therefore, in the $\mathrm{Co}(\mathrm{II})$ coordination complex reported in reference 33 and complex 1 from this work, the distances between metal centers are comparable: 6.143 and $5.43 \AA$, respectively. Accordingly to the $\theta_{(C-W)}$ and $E_{2}$ values of the three polymers, complex 1 possesses the less weak antiferromagnetic exchange. This situation could be explained by the different magnetic exchange pathways occurring in these complexes. In polymer $\mathbf{1}$ the main magnetic exchange 
corridor appears to be the strong hydrogen binding interactions occurring through the connections involving the coordinated water (05) and one of the oxygen atoms (03) in the carboxylate moiety of cdc ligand, belonging to a neighboring 1D complex molecule, [Co-O5-H5B-O3-Co] (Fig. S4c). Thus, these interactions produce the shortest $\mathrm{Co}-\mathrm{Co}$ distance of $5.43 \AA$ in the supramolecular structure of 1; on the other hand, in complexes $\mathbf{2}$ and $\mathbf{3}$ the shortest Co-Co distances are 8.84 and $8.22 \AA$, respectively. In these latter complexes, the hydrogen-bonding interactions (Figs. 1c and 2c) do not cause an approaching effect of metal ions in the corresponding supramolecular structures, as it occurs in $\mathbf{1}$. Hence, the shorter the distance between metal centers the larger is the corresponding $E_{2}$ value.

\section{Conclusions}

We have reported the synthesis and characterization of three crystalline $\mathrm{Co}$ (II) coordination polymers formed with 1,4-cyclohexanedicarboxylato and different 2,2'-bipyridine type co-ligands via self-assembly reactions. In complexes $\mathbf{1 - 3}$, the bridging cdc ligand coordination modes are monodentate $\eta^{1}$ and chelate bidentate $\eta^{2}$. these compounds have one-dimensional (1D) structures, where the Co metal centers are six-coordinated with a distorted-octahedral coordination sphere. Complexes $\mathbf{2}$ and $\mathbf{3}$ display a new bridging motif of the cdc ligand in its equatorial, axial cis configuration. Furthermore, the solid-state assemblies of the polymeric structures of 1-3 generate supramolecular frameworks, mainly through hydrogen bonding: 2D for complexes 1 and 3, and 1D for complex 2. The positive and low values for $E_{2}$ (Rueff phenomenological model) and the negative, and also low, values of $\theta_{(C-W)}$ (Curie-Weiss model), obtained in all three polymers, reveal weak antiferromagnetic exchange in these $\mathrm{Co}(\mathrm{II})$ systems.

\section{Acknowledgments}

Authors are thankful to M. en C. Alejandra Nuñez Pineda (CCIQS UAEM-UNAM) for elemental analysis. Funding for this work was provided by Universidad Autónoma del Estado de México. This work was also supported by CONACyT project 129293, DGAPAUNAM project IN106014, and ICYTDF, project PICCO. R.E. thanks to A. López, and A. Pompa-Garcia (IIM-UNAM), for help in computational and technical problems.

\section{Appendix A. Supplementary data}

Supplementary data associated with this article can be found, in the online version, at https://doi.org/10.1016/j.ica.2017.12.007.

\section{References}

[1] (a) R. Robson, Dalton Trans. (2008) 5113;

(b) C. Yamamoto, H. Nishikawa, M. Nihei, T. Shiga, M. Hedo, Y. Uwatoko, H. Sawa, H. Kitagawa, Y. Taguchi, Y. Iwasa, H. Oshio, Inorg. Chem. 45 (2006) 10270;

(c) H.C. Zhou, J.R. Long, O.M. Yaghi, Chem. Rev. 112 (2012) 673.

[2] G.R. Desiraju, J.J. Vittal, A. Ramanan, Crystal Engineering-A Text Book, IISc Press and World Scientific, Singapore, 2011.

[3] M. Dua, C.-P. Li, C.-S. Liub, S.-M. Fang, Coord. Chem. Rev. 257 (2013) 1282.

[4] D. Das, R. Banerjee, R. Mondal, J.A.K. Howard, R. Boese, G.R. Desiraju, Chem. Commun. (2006) 555.

[5] X.H. Zhou, L. Li, H.H. Li, A. Li, T. Yang, W. Huang, Dalton Trans. 42 (2013) 12403.

[6] D. Curiel, M. Más-Montoya, G. Sánchez, Coord. Chem. Rev. 284 (2014) 19.

[7] B.-H. Ye, M.-L. Tong, X.-M. Chen, Coord. Chem. Rev. 249 (2005) 545.

[8] D. Sun, M.-Z. Xu, S.-S. Liu, S. Yuan, H.-F. Lu, S.-Y. Feng, D.-F. Sun, Dalton Trans. 42 (2013) 12324

[9] A. Téllez-López, V. Sánchez-Mendieta, J. Jaramillo-García, L.D. RosalesVázquez, I. García-Orozco, R.A. Morales-Luckie, R. Escudero, F. Morales-Leal, Transition Met. Chem. 41 (2016) 879.

[10] L.D. Rosales-Vázquez, V. Sánchez-Mendieta, A. Dorazco-Gonzalez, D. MartínezOtero, I. García-Orozco, R.A. Morales-Luckie, J. Jaramillo-García, A. TellezLopez, Dalton Trans, 46 (2017) 12516.

[11] R.D. Hancock, Chem. Soc. Rev. 42 (2013) 1500.

[12] R. Alizadeh, V. Amani, Inorg. Chim. Acta 443 (2016) 151.

[13] L.B. Lopes, C.C. Corrêa, G.P. Guedes, M.G.F. Vaz, R. Diniz, F.C. Machado, Polyhedron 50 (2013) 16.

[14] G.M. Zhang, Y. Li, X.Z. Zou, J.A. Zhang, J.Z. Gu, A.M. Kirillov, Transition Met. Chem. 41 (2016) 153.

[15] APEX 2 software suite, Bruker AXS Inc., Madison, Wisconsin, USA

[16] G.M. Sheldrick, Acta Crystallogr. A 71 (2015) 3.

[17] C.B. Hübschle, G.M. Sheldrick, B. Dittrich, ShelXle, Appl. Cryst. 44 (2011) 1281.

[18] J. Do, Y. Lee, J. Kang, Y.S. Park, B. Lorenz, A.J. Jacobson, Inorg. Chem. 51 (2012) 3533.

[19] T.A. Beard, J.A. Wilson, R.L. LaDuca, Inorg. Chim. Acta 466 (2017) 30.

[20] C.C.R. Sutton, G. da Silva, G.V. Franks, Chem. Eur. J. 21 (2015) 6801.

[21] Y. Qi, Y. Wang, C. Hu, M. Cao, L. Mao, E. Wang, Inorg. Chem. 42 (2003) 8519.

[22] B.-J. Zhang, C.-J. Wang, G.-M. Qiu, S. Huang, X.-L. Zhou, J. Wenga, Y.-Y. Wang, Inorg. Chim. Acta 397 (2013) 48.

[23] J.-H. Guo, J. Chen, C.-P. Li, M. Du, J. Mol. Struct. 975 (2010) 147.

[24] Y. Xie, F.Y. Bai, J. Li, Y.H. Xing, Z. Wang, H.Y. Zhao, Z.F. Pu, M.F. Ge, Z. Shi, Spectrochimica Acta Part A 77 (2010) 749.

[25] X.-L. Wang, F.-F. Sui, H.-Y. Lin, J.-W. Zhang, G.-Ch. Liu, Cryst. Growth Des. 14 (2014) 3438.

[26] T.-F. Liu, J. Lü, R. Cao, Cryst. Eng. Comm. 12 (2010) 670.

[27] A.-Q. Ma, M.-X. Yu, L.-G. Zhu, Z. Kristallogr. NCS 219 (2004) 63.

[28] O. Kahn, Mol. Magn., VCH Publishers, New York, 1993.

[29] R.L. Carlin, Magnetochemistry, Springer-Verlag, Berlin, 1986.

[30] N.A. Protasenko, A.I. Poddel'sky, A.S. Bogomyakov, N.V. Somov, G.A. Abakumov, V.K. Cherkasov, Polyhedron 49 (2013) 239.

[31] P. Rabu, J.M. Rueff, Z.-L. Huang, S. Angelov, J. Souletie, M. Drillon, Polyhedron 20 (2001) 1677.

[32] (a) J.M. Rueff, N. Masciocchi, P. Rabu, A. Sironi, A. Skoulios, Eur. J. Inorg. Chem. (2001) 2843:

(b) J.M. Rueff, N. Masciocchi, P. Rabu, A. Sironi, A. Skoulios, Chem. Eur. J. 8 (2002) 1813.

[33] A. Téllez-López, J. Jaramillo-García, R. Martínez-Domínguez, R.A. MoralesLuckie, M.A. Camacho-López, R. Escudero, V. Sánchez-Mendieta, Polyhedron 100 (2015) 373. 